\title{
On the Correlation between Light-Induced Degradation and Minority Carrier Traps in Boron-Doped Czochralski Silicon
}

DOI:

10.1021/acsami.0c17549

\section{Document Version}

Accepted author manuscript

Link to publication record in Manchester Research Explorer

\section{Citation for published version (APA):}

Jafari, S., Zhu, Y., Rougieux, F., De Guzman, J. A. T., Markevich, V. P., Peaker, A. R., \& Hameiri, Z. (2021). On the Correlation between Light-Induced Degradation and Minority Carrier Traps in Boron-Doped Czochralski Silicon. ACS Applied Materials and Interfaces, 13(5), 6140-6146. https://doi.org/10.1021/acsami.0c17549

\section{Published in:}

ACS Applied Materials and Interfaces

\section{Citing this paper}

Please note that where the full-text provided on Manchester Research Explorer is the Author Accepted Manuscript or Proof version this may differ from the final Published version. If citing, it is advised that you check and use the publisher's definitive version.

\section{General rights}

Copyright and moral rights for the publications made accessible in the Research Explorer are retained by the authors and/or other copyright owners and it is a condition of accessing publications that users recognise and abide by the legal requirements associated with these rights.

\section{Takedown policy}

If you believe that this document breaches copyright please refer to the University of Manchester's Takedown Procedures [http://man.ac.uk/04Y6Bo] or contact uml.scholarlycommunications@manchester.ac.uk providing relevant details, so we can investigate your claim.

\section{OPEN ACCESS}




\title{
On the Correlation Between Light-Induced Degradation and Minority Carrier Traps in Boron-Doped Czochralski Silicon
}

\author{
Saman Jafari ${ }^{1}$, Yan Zhu ${ }^{1}$, Fiacre Rougieux ${ }^{1}$, Joyce Ann T. De Guzman ${ }^{2}$, Vladimir P. Markevich ${ }^{2}$, Anthony R. \\ Peaker $^{2}$ and Ziv Hameiri ${ }^{1 *}$ \\ ${ }^{1}$ The University of New South Wales, Sydney, NSW 2052, Australia \\ 2 The University of Manchester, Manchester M13 9PL, UK \\ * Corresponding author: z.hameiri@unsw.edu.au
}

\begin{abstract}
Boron-doped Czochralski grown silicon wafers dominate the photovoltaic market. Light-induced degradation of these wafers is one of the most significant roadblocks for high-efficiency solar cells. Despite a very large number of publications on this topic, only a few studies have directly investigated the precursor of the defect responsible for this degradation. In this study, using the photoconductance decay measurement method, we identify the precursor of the defect responsible for light-induced degradation. By comparing the photoconductance decay of samples in the different states, we observe the presence of a minority carrier trap in the annealed state which is not present after degradation. Trap annihilation shows a clear anticorrelation with the generation of the recombination active boron-oxygen defect, as determined from minority carrier lifetime measurements. Furthermore, it is concluded that a model based on a single-level trap cannot explain the doping-dependent measurements, meaning that the detected trap has two or more energy levels.
\end{abstract}

Keywords: boron-oxygen degradation, light-induced degradation, minority carrier traps, silicon, photoconductance decay

\section{Introduction}

Light-induced degradation (LID) of solar cells fabricated using boron-doped Czochralski (Cz) grown silicon wafers was first observed in 1973, showing a 3-5\% absolute reduction in efficiency after illumination under light for 12 hours. ${ }^{1}$ Since the degradation is linked to the simultaneous presence of boron and oxygen in the wafers, it is frequently called boron-oxygen (BO) degradation. ${ }^{2,3}$ Studies of the minority carrier lifetime of uncompensated wafers with various boron and oxygen concentrations have shown that the inferred concentration of the BO defect, which is responsible for LID, has a linear dependency on the boron concentration and a quadratic dependency on the oxygen concentration. ${ }^{4,5}$ It was found that LID in float zone (FZ) silicon wafers is negligible unless they are implanted with oxygen. ${ }^{6}$ It was also shown that LID is not common in gallium-doped $\mathrm{Cz}$ silicon wafers. ${ }^{7-9}$

It has been argued that the complex causing LID has three states: degraded state, annealed state, and stabilized state. ${ }^{4,10}$ The degraded state is reached via minority carrier injection resulting from exposure to light or from a forward bias current in a solar cell's p-n junction for several hours. ${ }^{1-13}$ After this carrier injection the bulk lifetime is reduced due to the transformation of the BO defect "precursor" to the recombination-active BO defect. ${ }^{14}$ The annealed state can be reached by dark annealing at elevated temperatures (typically around $200{ }^{\circ} \mathrm{C}$ ) for several minutes. In this state, the recombination-active defects transform back to the precursor form of the $\mathrm{BO}$ complex which is non-recombination active and does not affect the lifetime. However, this state is not stable and minority carrier injection reduces the lifetime again ${ }^{7}$. The stabilized state can be reached via carrier injection at elevated temperatures (around $200{ }^{\circ} \mathrm{C}$ ). ${ }^{10,15}$ At this state, the wafer is no longer prone to degradation under typical solar cell operating conditions. Nevertheless, this state is also meta-stable and can be transformed into the annealed state by a long dark annealing at high temperatures $\left(\sim 200{ }^{\circ} \mathrm{C}\right) .{ }^{15,16}$

In a recent study, a precursor of the recombination active $\mathrm{BO}$ defect has been observed in boron-doped $\mathrm{Cz}$ silicon samples by means of deep level transient spectroscopy (DLTS). ${ }^{17,18} \mathrm{~A}$ hole emission signal due to the BO defect in the annealed state was detected. The signal disappeared from the DLTS spectra after the degradation process. ${ }^{17}$ It was argued by the authors, and more recently in ${ }^{19}$, that a minority carrier trap (hereafter, a trap) is acting as a precursor for the recombination active BO defect. Furthermore, it has been suggested that in the degraded state the enhanced recombination occurs due to a shallow acceptor defect level through a trap-assisted Auger recombination process. ${ }^{18}$

Traps in silicon have been studied for decades. ${ }^{20-22}$ In general, traps in semiconductors can be defined as defect centers where the captured carriers are more likely to be temporarily trapped rather than permanently annihilated via recombination. While in several studies, traps are investigated using a steady-state assumption, it has been shown that such assumption is not always valid. ${ }^{23,24}$ In the pioneering work by Hornbeck and Haynes, traps in $p$ type boron-doped $\mathrm{Cz}$ silicon wafers were investigated using the photoconductance decay (PCD) method. Two types of traps were detected, one leads to a relatively short (milliseconds) and the other leads to a rather long (tens of seconds) PCD time constant. ${ }^{20}$ In a study by Schmidt et al. lifetime measurements were used to study traps in boron and gallium doped $\mathrm{Cz}$ silicon wafers. The authors found a correlation between the trap density and the 
interstitial oxygen concentration $\left[\mathrm{O}_{\mathrm{i}}\right]$ and suggested that this trap might be associated with the oxygen-related thermal double donors (TDDs). Furthermore, it has been argued that the origin of the trapping centres in their study is probably not identical to the LID-related recombination centres. ${ }^{25}$ In most previous studies, minority carrier traps in p-type Cz-silicon crystals were analysed as single-level defects with a deep energy level..$^{20,21}$ In recent studies ${ }^{17,18}$, it has been argued that the trapping effects in boron-doped $\mathrm{Cz}$ wafers are associated with transformations between deep donor and shallow acceptor configurations of a defect with a negative-U structure. ${ }^{26}$ This defect incorporates a substitutional boron atom and an oxygen dimer $\left(\mathrm{B}_{\mathrm{s}} \mathrm{O}_{2}\right){ }^{18}$

The impact of traps on photoconductance (PC)-based minority carrier lifetime measurements is a well-known effect. ${ }^{27,28}$ It has been shown that traps cause an artificially high apparent lifetime value at low, and sometimes, even medium injection levels. ${ }^{21}$ This occurs as the assumption that excess minority and majority carrier densities are equal is not valid anymore. In a $p$-type wafer, that has traps, after external excitation

$$
\Delta p=\Delta n+\Delta n_{\text {trap }}
$$

where $\Delta p(\Delta n)$ is the excess majority (minority) carrier density and $\Delta n_{\text {trap }}$ is the change in the density of filled traps after excitation. While some minority carriers recombine after excitation, others are temporarily captured by the traps. ${ }^{28}$ Thus, the remaining excess majority carriers are annihilated with a rate much smaller than the overall recombination rate. In PC-based lifetime measurements, the additional conductivity due to these majority carriers is misinterpreted as excess minority carriers ${ }^{29,30}$

$$
\Delta n_{a p p}=\Delta n+\left(\frac{\mu_{p}}{\mu_{n}+\mu_{p}}\right) \Delta n_{t r a p}
$$

where $\Delta n_{a p p}$ is the apparent carrier density measure via PC-based methods, and $\mu_{p}\left(\mu_{n}\right)$ is the hole (electron) mobility. Therefore, in these cases, the $\Delta n$ is different from $\Delta n_{a p p}$.

In this study, we first investigate trapping effects in boron-doped $\mathrm{Cz}$ silicon wafers in the annealed and degraded states using PCD measurements. Then, we correlate the change in the trap density with the density of recombination active $\mathrm{BO}$ defects after various degradation extents. Finally, using doping-dependent measurements, we show that the observed trap has multiple energy levels.

\section{Experimental section}

Three sets of boron-doped $\mathrm{Cz}$ silicon wafers with resistivities of $1.30 \pm 0.05 \Omega$.cm (Set 1), 0.70 $\pm 0.02 \Omega . \mathrm{cm}$ (Set 2) and $2.01 \pm 0.05 \Omega . \mathrm{cm}$ (Set 3 ) are used in this study. Initially, all wafers were gettered using phosphorous diffusion at $840{ }^{\circ} \mathrm{C}$ for $45 \mathrm{~min}$, followed by removal of the diffused layer using a hydrofluoric acid - nitric acid solution. Samples were then subjected to rapid thermal annealing (peak temperature of $800{ }^{\circ} \mathrm{C}$ for 10 seconds with a heating rate of $50{ }^{\circ} \mathrm{C} / \mathrm{min}$ ) to remove TDDs. ${ }^{24}$ The $\left[\mathrm{O}_{\mathrm{i}}\right]$ was then measured using Fourier transform infrared spectroscopy based on the ASTM standard (designations "F1188" and "F1391") modified for thin silicon wafers. ${ }^{31,32}$ The $\left[\mathrm{O}_{\mathrm{i}}\right]$ is measured to be $7 \times 10^{17} \mathrm{~cm}^{-3}$ for wafers from Sets 1 and 3 and $8 \times 10^{17} \mathrm{~cm}^{-3}$ for wafers from Set 2. Samples were then passivated with a $10 \mathrm{~nm}$ aluminum oxide $\left(\mathrm{AlO}_{\mathrm{x}}\right)$ layer using atomic layer deposition; this was later capped with a $75 \mathrm{~nm}$ silicon nitride $\left(\mathrm{SiN}_{\mathrm{x}}\right)$ layer (refractive index of 2.08 at $632 \mathrm{~nm}$ ) deposited using plasma-enhanced chemical vapor deposition. ${ }^{33} \mathrm{An}$ annealing process at $400{ }^{\circ} \mathrm{C}$ for 30 minutes was done after the $\mathrm{AlO}_{\mathrm{x}}$ deposition (before the $\mathrm{SiN}_{\mathrm{x}}$ deposition) to activate the surface passivation. We selected surface passivation methods that are known to have only a minor impact on the hydrogen content in the bulk.

For the degradation of the samples, two different methods were selected. Samples from Sets 2 and 3 and several samples from Set 1 were degraded at $120^{\circ} \mathrm{C}$ using $938 \mathrm{~nm}$ laser illumination (96 suns intensity). This method provides a fast degradation rate. ${ }^{34}$ The second group of samples from Set 1 were degraded at $60{ }^{\circ} \mathrm{C}$ using a set of halogen lamps with combined intensity of 1 sun. The degradation extent was monitored using PC lifetime measurements (WCT-120 from Sinton Instruments). To return the samples to its initial lifetime (annealed state), they were dark annealed at $200{ }^{\circ} \mathrm{C}$ for 15 minutes. Note that the reported temperatures are the actual sample temperatures (and not the set temperatures) determined by direct measurements of a monitor sample using k-type thermocouples.

PCD measurements were carried out at $45^{\circ} \mathrm{C}$ using our advanced lifetime tester. ${ }^{27}$ This system allows simultaneous measurements of both PC and photoluminescence (PL) signals in a wide range of temperatures. ${ }^{35,36}$ To improve the signal-to-noise ratio (SNR), 500 PCD measurements were averaged to generate each PCD graph. Furthermore, the measurement temperature was selected with the consideration of SNR. At $45{ }^{\circ} \mathrm{C}$, the PCD time constant is relatively short so that a large number of averaging is possible while the magnitude of the PC signal does not drop significantly compared with the room temperature signal. Sufficient time was given between two consecutive excitations to ensure the traps are empty before each measurement starts. For excitation, an X5DR flash head from Quantum Instruments (similar to the flash used in the WCT-120 lifetime tester) is used in the 1/64 mode, with a decay time constant of around $35 \mu \mathrm{s}$. This flash mode was selected to minimize possible degradation 
induced by flash illumination. Lifetime measurements at $30^{\circ} \mathrm{C}$, using the same system under quasi-steady state (QSS) condition, were done before and after each of the PCD measurements to monitor possible measurementinduced degradation.

Fitting of the PCD curves is done using a mono-exponential decay function in the form of

$$
\Delta \sigma=a \cdot \exp \left(\frac{-t}{\tau_{\text {decay }}}\right)
$$

where $\Delta \sigma$ is the photoconductivity, $a$ is the pre-exponential factor proportional to the number of filled traps after the flash (see more below), $t$ is time after the excitation, and $\tau_{\text {decay }}$ is the PCD time constant.

To monitor the partial degradation extent, the normalized defect density (NDD) of the recombination active BO defect was calculated using

$$
N D D=\left(\frac{1}{\tau_{\operatorname{deg}(t)}}-\frac{1}{\tau_{D A}}\right) /\left(\frac{1}{\tau_{\operatorname{deg}(8 h)}}-\frac{1}{\tau_{D A}}\right),
$$

where $\tau_{\operatorname{deg}(t)}$ is the effective lifetime after light soaking for $t$ minutes and $\tau_{D A}$ is the effective lifetime after dark annealing. The denominator is the harmonic difference of lifetimes between the degraded state (light soaking with halogen lamps for eight hours at $60{ }^{\circ} \mathrm{C}$ ) and the annealed state. All the values are given at $\Delta n$ of $1.1 \times 10^{15} \mathrm{~cm}^{-3}$ $\left(0.1 \times p_{0} \mathrm{~cm}^{-3}\right.$, where $p_{0}$ is the bulk doping).

\section{Results and discussion}

\section{Presence of traps in the annealed state}

Figure 1 (a) shows the lifetime of a representative sample from Set 1 (at $30^{\circ} \mathrm{C}$ ) in the annealed and degraded (with the laser-based process) states. As expected, the effective lifetime in the annealed state is higher than the effective lifetime after the degradation process. Cycling the sample between the two states (annealed and degraded) results in a shift between the two lifetime curves. Figure 1 (b) shows the PCD curves (at $45{ }^{\circ} \mathrm{C}$ ) for the same sample after each process. Interestingly, the transformation between the two states strongly matches a change in the PCD curves. These curves show that the PC signal increases significantly after the excitation by the flash due to external carrier generation. After this increase, the PC drops considerably due to carrier recombination. In the annealed state, this initial decrease in the PC is followed by a much slower second decay with a time constant of several seconds. Since the sample is passivated with a negatively charged dielectric, this effect cannot be explained by depletion region modulation (DRM). ${ }^{37,38}$ Thus, it appears that this long decay is due to the presence of minority carrier traps in the annealed state. However, for samples in the degraded state (where the BO defect is already formed), the initial decay due to carrier recombination continues until the PC signal returns to its value in the dark (which is within the range of the noise level of our system). The absence of the long PCD tail indicates that the traps that exist in the annealed state are removed due to degradation. As it is shown in Figure 1 (b), this transformation is reversible. In accordance with the change in lifetime, the traps are formed and annihilated during the dark annealing-degradation cycles. Similar results are obtained when the degradation is done using a halogen lamp and in the wafers with different resistivity (from Sets 2 and 3).

It is important to note that the observed trapping effect (persistent PC) is not related to thermal donors as thermal donors were removed in all wafers used in this study via a thermal donor annihilation step. Moreover, similar traps were not observed in boron-doped $\mathrm{FZ}$ and phosphorus-doped $\mathrm{Cz}$ silicon wafers after the dark annealing process (Appendix A). In the next section, we investigate whether the trap is related to the recombination active BO defects, or whether its change during the dark annealing-degradation cycle is coincidental.

The slow decay of the PCD in the annealed state has a linear shape in the $\log P C$ - time curve, suggesting a mono-exponential decay of the PC signal. By fitting this section of the curve with Equation (3), the average decay time constant is determined to be $15.9 \pm 0.8 \mathrm{~s}$ at $45^{\circ} \mathrm{C}$ for the samples from Set 1 . It should be mentioned that the removal of TDDs has a significant impact on the decay. We observe another trap in the samples from Set 3 which were not subjected to the TDD removal step. In the annealed state, the samples display PCD curves with two long decay slopes, while after the degradation process one of the slopes is removed (Appendix B). Removing TDDs using the above-mentioned process also removes the second slope, associated with the TDDs. This indicates that TDDs are correlated to one type of traps in p-type $\mathrm{Cz}$ silicon. This result supports a suggestion by Schmidt et al. that the traps detected in their oxygen-rich $\mathrm{Cz}$ silicon wafers can be related to TDDs. ${ }^{25}$ However, in this study we focus on the second detected trap, which is not related to TDDs.

As shown in Figure 1 (a), the trapping effect is not observable in our lifetime measurements, meaning $\Delta n=\Delta n_{a p p}$ for the range of excess minority carriers shown in this figure. This can be explained in two ways: 
1. The trap density is too small to be detected in the common measurement range. Using constant electron and hole mobility values, $\Delta n_{a p p}$ is calculated and displayed on the right $y$-axis of Figure 1 (b). ${ }^{39}$ We estimate an error less than $10 \%$ in $\Delta n_{a p p}$ due to the simplification of mobility, even at the highest injection level. As can be seen, the traps are noticeable only for $\Delta n_{\text {app }}$ below $10^{13} \mathrm{~cm}^{-3}$, a region where common lifetime measurements suffer from a high level of noise.

2. Due to ambient light or a short waiting time between consecutive flashes, a considerable portion of traps is still occupied during the following measurement. For instance, the lifetime of our samples is obtained by averaging 10 measurements with 15 seconds between consecutive flashes. Considering a PCD time constant of $29 \mathrm{sec}$ at $30{ }^{\circ} \mathrm{C}$, almost $60 \%$ of the traps are still occupied when the second measurement starts. These occupied traps will be considered as the dark (background) conductance for the following measurements and will be removed by subtraction. Thus, for trap investigation, it is important to wait for a sufficiently long time between flashes to guarantee the traps are empty before the next measurement.
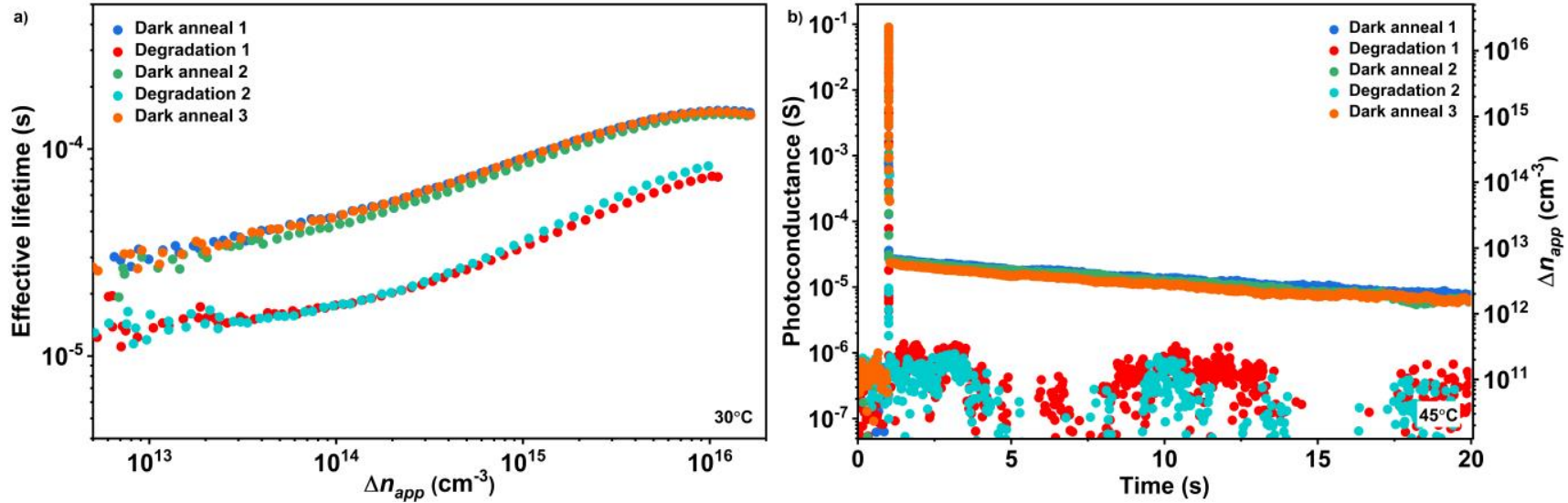

Figure 1. (a) Effective lifetime measurements at $30{ }^{\circ} \mathrm{C}$ and (b) PCD measurements at $45^{\circ} \mathrm{C}$ for a sample going through dark annealingdegradation cycles (Set 1).

To gain a better understanding regarding the relationship between the observed trap and the recombination active BO defect, we now investigate the change in trap density and the normalized defect density after partial degradation. The defect's density is extracted from the lifetime curve using the NDD metric [Equation (4)]. It is assumed that the normalized trap density is proportional to $a$ of Equation (3). However, this assumption needs to be verified. At injection levels where $\Delta n_{\text {trap }}>>\Delta n$,

$$
\Delta \sigma=q w\left(\mu_{p} \Delta n_{\text {trap }}\right)
$$

where $q$ is the elementary charge and $w$ is the sample thickness. At $t=0, \Delta n_{\text {trap }}$ is proportional to $a$; the preexponential factor is a measure of the density of traps that are filled after excitation. The number of filled traps is a function of the trap occupancy ratio $\left(f_{t}\right)$ and the total number of traps $\left(N_{t}\right)^{40}$

$$
a \propto \Delta n_{\text {trap }}=\left(f_{t}(\Delta n, T)-f_{t 0}\right) N_{t},
$$

which means that the change in $a$ can either be due to a change in trap density or occupancy ratio. In this equation, $f_{t 0}$ is the filling ratio in the dark. As indicated in Equation (6), the occupancy ratio of the traps is a function of $\Delta n$ and temperature. ${ }^{40}$ Since all the PCD measurements are done at the same temperature $\left(45^{\circ} \mathrm{C}\right), T$ is constant. However, due to the lower lifetime after degradation, $\Delta n$ is reduced, possibly impacting $a$. Hence, it is possible that the variation in $a$ are due to changes in $\Delta n$, not $N_{t}$.

To investigate this possibility, the PCD of a sample in the annealed state is measured in a $\Delta n$ range significantly lower than $\Delta n$ of the degraded state. This is done using a neutral density (ND) filter in front of the flash. Figure 2 (a) shows PCD measurements of a sample in the annealed state with and without the ND filter, along with the measurement in the degraded state. Figure 2 (b) presents the change in $\Delta n_{\text {app }}$ as a function of time for these three measurements. Since the peak of $\Delta n_{a p p}$ is at a high injection level and no effect of traps on the lifetime curve can be observed at this injection level [Figure 1(a)], we assume that $\Delta n_{\text {app }}=\Delta n$. As can be seen, the ND filter reduces the maximum $\Delta n$ in the annealed sample to a range significantly lower than $\Delta n$ of the fully degraded state. However, even when the filter is used, the traps remain visible. The determined $a$ values for the annealed states with and without the ND filter are almost identical $\left(2 \times 10^{-5} \pm 5 \times 10^{-7} \mathrm{~S}\right.$ vs $\left.2.15 \times 10^{-5} \pm 5 \times 10^{-7} \mathrm{~S}\right)$. This is clear evidence that the occupancy ratio in these two measurements is not influenced by the reduction in $\Delta n$. Knowing 
that the occupancy ratio is a monotonic function of $\Delta n$ (Appendix $\mathrm{C}$ ), it can be concluded that its change is negligible in the relevant range of $\Delta n$. Therefore, we conclude that $a$ is indeed proportional to the trap density.
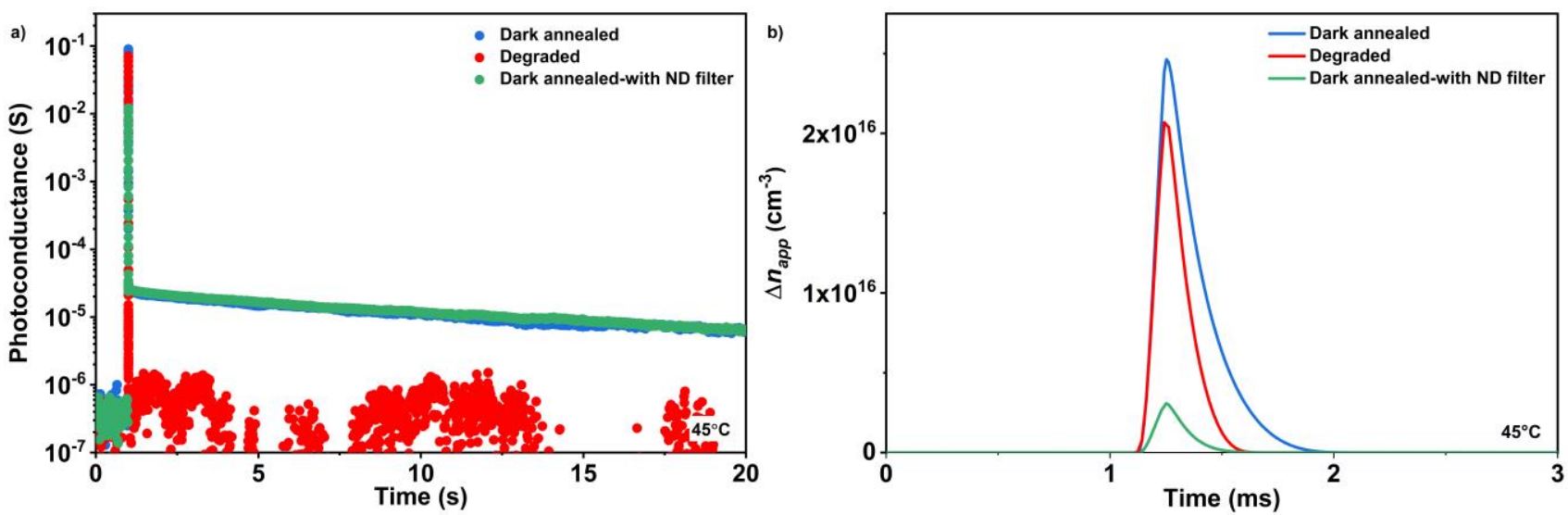

Figure 2. (a)PCD measurements for a sample in the annealed state with and without ND filter and in the degraded state without ND filter. (b) The corresponding apparent carrier density in the sample for each measurement (Set 1).

We can now study the changes in trap and defect density after partial degradation. Figure 3 shows these two densities as a function of light soaking duration. A clear anticorrelation can be observed between the generation of $\mathrm{BO}$ defects and the annihilation of traps. Both densities demonstrate an exponential dependence on light soaking time.

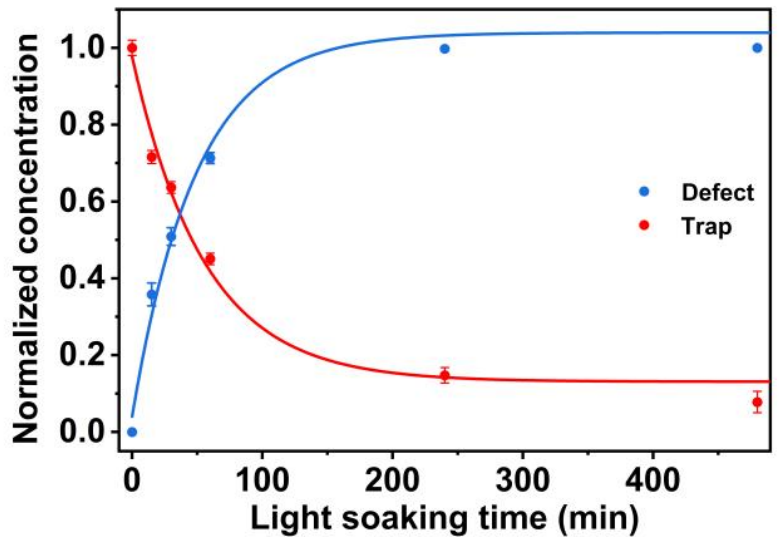

Figure 3. Evolution of the trap and defect density of a sample after various light soaking durations under 1 sun illumination at $60{ }^{\circ} \mathrm{C}$. The solid lines show the fitted curves using exponential functions (Set 1).

Simultaneous fitting of the experimental data in Figure 3 with a mono-exponential function (R-squared of 0.98), a time constant of $54 \pm 5 \mathrm{~min}$ is determined for the changes of trap density and NDD. This value is in good agreement with the previously reported value $(\sim 52 \mathrm{~min})$ for the generation rate of slow-formed BO defect centers in a boron-doped wafer $\left(10^{16} \mathrm{~cm}^{-3}\right.$ boron concentration and $7-8 \times 10^{17} \mathrm{~cm}^{-3}$ oxygen concentration) degraded under 0.1 sun illumination at $60{ }^{\circ} \mathrm{C} .{ }^{41}$ As it has been shown that the degradation rate is almost independent of illumination intensity in the range of 0.01-1 sun, ${ }^{42}$ the values reported by Bothe et al., ${ }^{41}$ can be directly compared with the value determined in this study. This result suggests that the traps act as a precursor for the recombination active $\mathrm{BO}$ defect. The obtained results confirm the observations of anticorrelation between the densities of minority carrier trap and the recombination active $\mathrm{B}_{\mathrm{s}} \mathrm{O}_{2}$ center measured with DLTS method in n+-p and Schottky diodes in B-doped $\mathrm{Cz}$ silicon crystals. ${ }^{17,18}$ The degradation rate time constants of the other two $\mathrm{Cz}$ wafers also match well with the values reported previously, having a correlation with the square of hole density. ${ }^{41}$

Previous study ${ }^{22}$ has shown that for a single level trap in a $p$-type wafer at low injection level $\left(p_{0}>>\Delta n\right)$ with negligible minority carrier re-capturing, the relationship between the PCD time constant and trap parameters can be described by

$$
\frac{1}{\tau_{\text {decay }}}=\sigma_{p} v_{p} p_{0}+\left(\sigma_{n} v_{n} n_{1}+\sigma_{p} v_{p} p_{1}\right)
$$

where $\sigma_{p}\left(\sigma_{n}\right)$ is the hole (electron) capture cross section, $v_{p}\left(v_{n}\right)$ is the hole (electron) thermal velocity ${ }^{43}$ and, $p_{0}$ is the hole concentration in thermal equilibrium. The parameters $n_{l}$ and $p_{l}$ are defined as $n_{i} \exp \left[\left(E_{t}-E_{i}\right) / k_{B} T\right]$ and $n_{i}$ 
$\exp \left[\left(E_{i}-E_{t}\right) / k_{B} T\right]$, where $n_{i}$ is the intrinsic carrier concentration ${ }^{44}, E_{t}$ and $E_{i}$ are the defect energy level and intrinsic energy level, respectively, $k_{B}$ is the Boltzmann constant and $T$ is the temperature in Kelvin. If the assumptions for Equation (7) are fulfilled (see discussion in Appendix D), by having samples with different resistivities and generating $1 / \tau_{\text {decay }}$ vs. $v_{p} p_{0}$ curve, $\sigma_{p}$ can be extracted from the slope. ${ }^{22}$ Note that the intercept with the $1 / \tau_{\text {decay }}$ axis should always be positive since both the second and third terms are always positive.

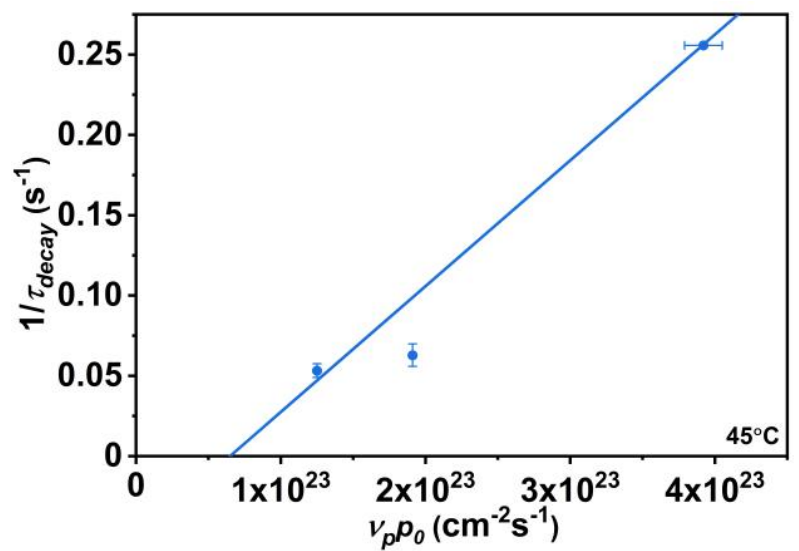

Figure 4. Doping-dependent measurement of the PCD time constant for three samples with different resistivities. The solid line shows a fit with a linear function.

Using the data obtained for three sets of samples, Figure 4 presents $1 / \tau_{\text {decay }}$ (measured at $45{ }^{\circ} \mathrm{C}$ ) as a function of $v_{p} p_{0}$ after dark annealing. It also shows the linear function that provides the best fit (R-squared of 0.96). The fitted curve has a slope of $8.1 \times 10^{-25} \mathrm{~cm}^{2}$ and an intercept of $-0.06 \mathrm{~s}^{-1}$. Despite the low-quality fit, it is clear that the intercept value is negative, indicating that Equation (7) is not suitable to describe the trap investigated here. This means that one of the assumptions is incorrect. As the assumption of negligible minority carrier re-capture and low injection level has been confirmed as discussed in Appendix D, the fact that Equation (7) cannot describe the doping dependent measurement result indicates that this trap is not a single-level trap. This conclusion is consistent with the results obtained previously on the electronic structure of the minority carrier trap in $\mathrm{B}-\mathrm{doped} \mathrm{Cz}$ silicon. ${ }^{17,18}$ It is further supported by temperature-dependent measurements of PCD, discussed in Appendix E.

\section{Conclusions}

In this study, LID in boron-doped $\mathrm{Cz}$ silicon wafers was investigated using PCD measurements. A noticeable change in the density of traps was observed upon degradation and dark annealing processes. Moreover, the trap annihilation and BO defect formation rates were shown to be the same. All evidence points to the fact that the traps are correlated with the precursor of the recombination active $\mathrm{BO}$ defect. For our samples with $p_{0}=$ $1.1 \times 10^{16} \mathrm{~cm}^{-3}$, under 1 sun illumination at $60^{\circ} \mathrm{C}$, this precursor transforms to the recombination active form with a time constant of $54 \pm 5 \mathrm{~min}$. Finally, using doping-dependent measurement of PCD time constants, it was shown that this trap has multiple energy levels.

This study clearly demonstrates the potential of PCD measurements as a tool to investigate defects in their nonrecombination active form, complementing the PC-based lifetime measurement technique for defect studies.

\section{Acknowledgement}

The authors wish to thank Mr. Thien Truong (from ANU) for helping with the sample passivation. This work was supported by the Australian Government through the Australian Renewable Energy Agency (ARENA) under grant 2017/RND001 and in Manchester by the EPSRC under grant EP/T025131/1. Yan Zhu acknowledges the support by ACAP fellowship (Australian Centre for Advanced Photovoltaics, project RG200768-G). The views expressed herein are not necessarily the views of the Australian Government, and the Australian Government does not accept responsibility for any information or advice contained herein.

Supporting Information Available: PCD measurement of boron-doped FZ and phosphorus-doped Cz silicon wafers, PCD of samples before TDDs removal, Occupancy ratio as a function of excess carrier density, Investigating assumptions of Equation 7, Temperature-dependent measurement

\section{References}

(1) Fischer, H.; Pschunder, W. Investigation of Photon and Thermal Induced Changes in Silicon Solar Cells; Proc. 10th IEEE Photovol. Spec. Conf. 1973, 404-411.

Glunz, S. W.; Rein, S.; Warta, W.; Knobloch, J.; Wettling, W. On the Degradation of Cz-Silicon Solar Cells. Proc. 2nd World Conf. Photovolt. Sol. Energy Conversion 1998, 1343-1346. 
(3) Rein, S.; Diez, S.; Falster, R.; Glunz, S. W. Quantitative Correlation of the Metastable Defect in CZSilicon with Different Impurities. Proc. 3rd World Conf. Photovolt. Sol. Energy Conversion 2003, 2, 1048-1052.

(4) Niewelt, T.; Schon, J.; Warta, W.; Glunz, S. W.; Schubert, M. C. Degradation of Crystalline Silicon Due to Boron-Oxygen Defects. IEEE J. Photovoltaics 2017, 7, 383-398.

(5) Schmidt, J.; Bothe, K. Structure and Transformation of the Metastable Boron- and Oxygen-Related Defect Center in Crystalline Silicon. Phys. Rev. B - Condens. Matter Mater. Phys. 2004, 69, 1-8.

(6) Glunz, S. W.; Rein, S.; Warta, W.; Knobloch, J.; Wettling, W. Degradation of Carrier Lifetime in Cz Silicon Solar Cells. Sol. Energy Mater. Sol. Cells 2001, 65, 219-229.

(7) Schmidt, J.; Aberle, A. G.; Hezel, R. Investigation of Carrier Lifetime Instabilities in Cz-Grown Silicon. Proc. 26th IEEE Photovol. Spec. Conf. 1997, 13-18.

(8) Glunz, S. W.; Rein, S.; Knobloch, J.; Wettling, W.; Abe, T. Comparison of Boron- and Gallium-Doped p-Type Czochralski Silicon for Photovoltaic Application. Prog. Photovoltaics Res. Appl. 1999, 7, 463469.

(9) Arivanandhan, M.; Gotoh, R.; Fujiwara, K.; Uda, S. Effects of B and Ge Codoping on Minority Carrier Lifetime in Ga-Doped Czochralski-Silicon. J. Appl. Phys. 2009, 106, 013721.

(10) Herguth, A.; Schubert, G.; Kaes, M.; Hahn, G. Avoiding Boron-Oxygen Related Degradation in Highly Boron Doped Cz Silicon. Proc. 21st Eur. Photovolt. Solar Energy Conf. 2006; 530-537.

(11) Knobloch, J.; Glunz, S. W.; Biro, D.; Warta, W.; Schaffer, E.; Wettling, W. Solar Cells with Efficiencies above 21\% Processed from Czochralski Grown Silicon. Proc. 25 th IEEE Photovol. Spec. Conf. 1996, 405-408.

(12) Hashigami, H.; Itakura, Y.; Saitoh, T. Effect of Illumination Conditions on Czochralski-Grown Silicon Solar Cell Degradation. J. Appl. Phys. 2003, 93, 4240-4245.

(13) Bothe, K.; Hezel, R.; Schmidt, J. Recombination-Enhanced Formation of the Metastable Boron-Oxygen Complex in Crystalline Silicon. Appl. Phys. Lett. 2003, 83, 1125-1127.

(14) Schmidt, J.; Lim, B.; Walter, D.; Bothe, K.; Gatz, S.; Dullweber, T.; Altermatt, P. P. Impurity-Related Limitations of Next-Generation Industrial Silicon Solar Cells. IEEE J. Photovoltaics 2013, 3, 114-118.

(15) Lim, B.; Bothe, K.; Schmidt, J. Deactivation of the Boron-Oxygen Recombination Center in Silicon by Illumination at Elevated Temperature. Phys. status solidi-Rapid Res. Lett. 2008, 2, 93-95.

(16) Herguth, A.; Hahn, G. Kinetics of the Boron-Oxygen Related Defect in Theory and Experiment. J. Appl. Phys. 2010, 108, 114509.

(17) Markevich, V. P.; Vaqueiro-Contreras, M.; De Guzman, J. T.; Coutinho, J.; Santos, P.; Crowe, I. F.; Halsall, M. P.; Hawkins, I.; Lastovskii, S. B.; Murin, L. I.; Peaker, A. R. Boron-Oxygen Complex Responsible for Light Induced Degradation in Silicon Photovoltaic Cells: A New Insight into the Problem. Phys. Status Solidi 2019, 216, 1900315.

(18) Vaqueiro-Contreras, M.; Markevich, V. P.; Coutinho, J.; Santos, P.; Crowe, I. F.; Halsall, M. P.; Hawkins, I.; Lastovskii, S. B.; Murin, L. I.; Peaker, A. R. Identification of the Mechanism Responsible for the Boron Oxygen Light Induced Degradation in Silicon Photovoltaic Cells. J. Appl. Phys. 2019, 125, 185704.

(19) Jafari, S.; Zhu, Y.; Rougieux, F.; De Guzman, J. A. T.; Markevich, V. P.; Peaker, A. R.; Hameiri, Z. Boron-Oxygen Related Light-Induced Degradation of Si Solar Cells: Transformation between Minority Carrier Traps and Recombination Active Centers. Proc. 47 th IEEE Photovol. Spec. Conf. 2020.

(20) Hornbeck, J. A.; Haynes, J. R. Trapping of Minority Carriers in Silicon. I. P-type silicon. Phys. Rev. 1955, 97, 311-321.

(21) Cuevas, A.; Stocks, M.; McDonald, D.; Kerr, M.; Samundsett, C. Recombination and Trapping in Multicrystalline Silicon. IEEE Trans. Electron Devices 1999, 46, 2026-2034.

(22) Zhu, Y.; Juhl, M. K.; Coletti, G.; Hameiri, Z. Reassessments of Minority Carrier Traps in Silicon With Photoconductance Decay Measurements. IEEE J. Photovoltaics 2019, 9, 652-659.

(23) Zhu, Y.; Juhl, M.; Coletti, G.; Hameiri, Z. Reassessment of Minority Carrier Traps in Silicon during "QuasiSteady-State" Photoconductance Measurements. Proc. IEEE 7th World Conf. Photovolt. Energy Conversion 2018, 0077-0088.

(24) Hu, Y.; Schøn, H.; Nielsen, Ø.; Johannes Øvrelid, E.; Arnberg, L. Investigating Minority Carrier Trapping in N-Type Cz Silicon by Transient Photoconductance Measurements. J. Appl. Phys. 2012, 111, 053101.

(25) Schmidt, J.; Bothe, K.; Hezel, R. Oxygen-Related Minority-Carrier Trapping Centers in p -Type Czochralski Silicon. Appl. Phys. Lett. 2002, 80, 4395-4397.

(26) Coutinho, J.; Markevich, V. P.; Peaker, A. R. Characterisation of Negative- U Defects in Semiconductors. J. Phys. Condens. Matter 2020, 32, 323001.

(27) Sinton, R. A.; Cuevas, A.; Stuckings, M. Quasi-Steady-State Photoconductance, a New Method for Solar Cell Material and Device Characterization. Proc. 25 th IEEE Photovol. Spec. Conf. 1996, 457-460.

(28) Macdonald, D.; Cuevas, A. Trapping of Minority Carriers in Multicrystalline Silicon. Appl. Phys. Lett. 1999, 74, 1710-1712. 
(29) Bardos, R. A.; Trupke, T.; Schubert, M. C.; Roth, T. Trapping Artifacts in Quasi-Steady-State Photoluminescence and Photoconductance Lifetime Measurements on Silicon Wafers. Appl. Phys. Lett. 2006, 88, 053504.

(30) McIntosh, K. R.; Paudyal, B. B.; Macdonald, D. H. Generalized Procedure to Determine the Dependence of Steady-State Photoconductance Lifetime on the Occupation of Multiple Defects. J. Appl. Phys. 2008, 104, 084503.

(31) Boyle, R. FT-IR Measurement of Interstitial Oxygen and Substitutional Carbon in Silicon Wafers. Madison, WI, USA, 2008.

(32) Soiland, A.-K. Silicon for Solar Cells. 2004, NTNU.

(33) Hameiri, Z.; Borojevic, N.; Mai, L.; Nandakumar, N.; Kim, K.; Winderbaum, S. Low-Absorbing and Thermally Stable Industrial Silicon Nitride Films With Very Low Surface Recombination. IEEE J. Photovoltaics 2017, 7, 996-1003.

(34) Payne, D. N. R.; Chan, C. E.; Hallam, B. J.; Hoex, B.; Abbott, M. D.; Wenham, S. R.; Bagnall, D. M. Acceleration and Mitigation of Carrier-Induced Degradation in p-Type Multi-Crystalline Silicon. Phys. status solidi - Rapid Res. Lett. 2016, 10, 237-241.

(35) Vargas, C.; Zhu, Y.; Coletti, G.; Chan, C.; Payne, D.; Jensen, M.; Hameiri, Z. Recombination Parameters of Lifetime-Limiting Carrier-Induced Defects in Multicrystalline Silicon for Solar Cells. Appl. Phys. Lett. 2017, 110, 092106.

(36) Zhu, Y.; Hameiri, Z. Review of Injection Dependent Charge Carrier Lifetime Spectroscopy. Prog. Energy. 2020.

(37) Cousins, P. J.; Neuhaus, D. H.; Cotter, J. E. Experimental Verification of the Effect of Depletion-Region Modulation on Photoconductance Lifetime Measurements. J. Appl. Phys. 2004, 95, 1854-1858.

(38) Bail, M.; Schulz, M.; Brendel, R. Space-Charge Region-Dominated Steady-State Photoconductance in Low-Lifetime Si Wafers. Appl. Phys. Lett. 2003, 82, 757-759.

(39) Klaassen, D. B. M. A Unified Mobility Model for Device Simulation-I. Model Equations and Concentration Dependence. Solid. State. Electron. 1992, 35, 953-959.

(40) Sun, C.; Rougieux, F. E.; Macdonald, D. A Unified Approach to Modelling the Charge State of Monatomic Hydrogen and Other Defects in Crystalline Silicon. J. Appl. Phys. 2015, 117, 045702.

(41) Bothe, K.; Schmidt, J. Electronically Activated Boron-Oxygen-Related Recombination Centers in Crystalline Silicon. J. Appl. Phys. 2006, 99, 013701.

(42) Voronkov, V. V.; Falster, R.; Schmidt, J.; Bothe, K.; Batunina, A. V. Lifetime Degradation in Boron Doped Czochralski Silicon. ECS Transactions 2010, 33, 103-112.

(43) Green, M. A. Intrinsic Concentration, Effective Densities of States, and Effective Mass in Silicon. J. Appl. Phys. 1990, 67, 2944-2954.

(44) Couderc, R.; Amara, M.; Lemiti, M. Reassessment of the Intrinsic Carrier Density Temperature Dependence in Crystalline Silicon. J. Appl. Phys. 2014, 115, 093705. 
TOC Graphic

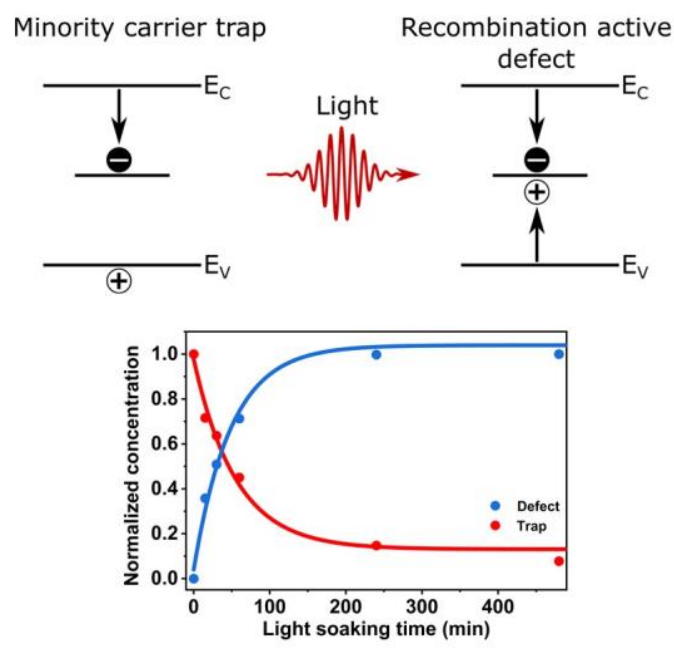

